\title{
Influence of Self Motivation on Mental Health of Elderly People
}

\author{
Canrui Chen $^{1 *}$, Jiajian Huang ${ }^{1}$, Herui Shang ${ }^{1}$ \\ ${ }^{1}$ Psychological Department, Guangzhou Medical University, Guangzhou \\ 510182, P.R. China.
}

* Corresponding Author: Canrui Chen, MD, Guangzhou Medical University, Guangzhou, P.R. China. Email: chencanrui2006@126.com.

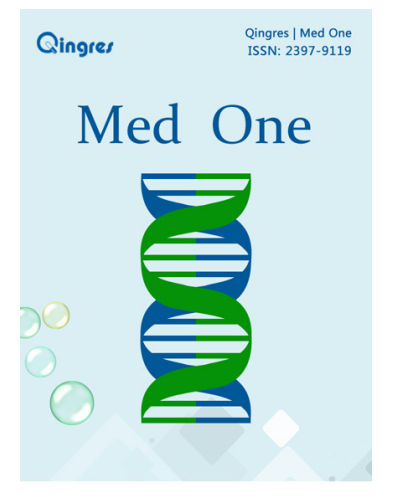

http://mo.qingres.com

\section{GOPEN ACCESS}

DOI: $10.20900 / \mathrm{mo} .20160021$

Received: July 12, 2016

Accepted: September 13, 2016

Published: October 25, 2016

Copyright: $\odot 2016$ Cain et al. This is an open access article distributed under the terms of the Creative Commons Attribution License, which permits unrestricted use, distribution, and reproduction in any medium, provided the original author and source are credited.

\begin{abstract}
Objective: To study the influence of self-motivation characteristics on the mental health of the elderly.

Methods: Life Satisfaction Rating Scales A (LSRA), UCLA Loneliness Scale, and the Mandala Painting Method (MPM) were used to assess 189 elderly people in the Home for the Aged Guangzhou. The mean age was 65.32 years.

Results: a. The self-motivation of the elderly gives priority to the integration stage (35\%) and the protection stage (23.3\%); b. Elderly women have a significantly greater life satisfaction, Mandala integration feature, transcendental characteristics and a significantly lower Ioneliness scores than elderly men; c. Regression analysis shows that peaceful moods occurring during painting can explain $11 \%$ of the life satisfaction, while an increased peripheral color and a focused moods during painting may explain $26 \%$ of the loneliness.
\end{abstract}

Conclusion: Self-motivation characteristics affect the mental health of the elderly.

Key Words: Mandal Painting; Elderly people; Life Satisfaction; Loneliness

\section{INTRODUCTION}

China's population is aging with the result being that more and more attention is paid to the mental health of elderly people. Life satisfaction and loneliness are closely related to the mental health of the elderly. The mental health of the elderly is based on positive and negative moods, or emotions ${ }^{[1]}$, which are important mental health indicators. Studies show a significant negative correlation between life satisfaction 
and loneliness ${ }^{[2]}$. Scholars have found that gender, education level, health status, and coping style greatly impact mental health ${ }^{[3]}$.

Psychoanalysis contends that engaged, and calibrated, self-motivation is the core factor affecting mental health ${ }^{[4]}$. Self is the central concept in psychoanalytic theory and Jung posited the self as organizing and coordinating personality ${ }^{[5]}$. The self is composed of self-motivation, emotional experience, and self-image ${ }^{[6]}$. Disorders of these self functions greatly affect individual mental health. People experience anxiety, depression, and other negative emotions when their self-motivation is dysfunctional, while smooth performance allows for more positive emotions ${ }^{[6]}$.

Jung argues that dysfunctioning self-motivation may be represented in mandala painting works ${ }^{[7]}$. A mandala is a self-typical image that it is a pictorial manifestation of self-motivation. Researchers have created mandala painting templates to correspond to self-motivation ${ }^{[8]}$. These templates effectively reflect the painter's stage of self-motivation ${ }^{[4]}$. Up to the present, the MPM has been effectively used in psychological assessment and therapy ${ }^{[9-12]}$. Some scholars have used the MPM by to assess Alzheimer severity in patients ${ }^{[13]}$. There are few empirical studies of the influence of self-motivation on elderly mental health.

Is there empirical support for the psychoanalytic hypothesis that mental health can be influenced by self-motivation? Answers to this question has theoretical significance for analyzing any models of mental and pathological theory and also practical value for elderly mental health evaluation and treatment. This study aims to examine relationships between self-motivation and elderly mental health via the MPM, including: what are the stages of selfdetermination in the elderly? Are there any gender differences in self-motivation characteristics? Does the MPM predict loneliness and life satisfaction in the elderly?

\section{SUBJECTS AND METHODS}

\subsection{Subjects}

A total of 189 potential subjects chosen at random from the resident population of the Home for the Aged Guangzhou. A total of 181 subjects were selected. Invalid questionnaires resulted in 8 potential subjects being rejected. There were 61 male and 120 female subjects. The mean age was 65.32.

\subsection{Research Means}

\subsubsection{Life Satisfaction Rating Scale (LSRA)}

The LSRA was developed by Edward Dana in 1980. It has 20 questions and uses scoring method of 0,1 , and 2. The higher the LSRA score is, the higher the life satisfaction is. Scorer reliability was 0.78 for our subjects.

\subsubsection{UCLA Loneliness Scale}

The UCLA loneliness scale was developed by Russell. It has 20 questions and uses $A$ four-level scoring method. The higher the score, the more pronounce loneliness will be. Internal consistency was 0.89 and retest reliability was 0.73 for our subjects.

\subsubsection{Mandala Template}

Mandala templates representing six motivation stages of the self were selected from 173 mandala paintings in "The Road of Mind-Self-Healing Picture Book" by Canrui Chen ${ }^{[7]}$, and Yanhong Gao. These templates purport to accurately reflect the stage of self-motivation of the painters.

\subsubsection{Mandala Characteristic Scale}

A Mandala Characteristic Scale (28 questions) prepared by Canrui Chen ${ }^{[4]}$ was used. It was analyzed using a five-level scoring method and mandala characteristics were analyzed based on painting structure, color, line, image, and painting emotions. The scale was divided into five "sense of" factors: security; order; coherence; integration; and the sacred. The higher score the score the stronger is painter's self-motivation.

\subsubsection{Painting Tools}

There were 24-color Chinese Brand colored pencils, one Chinese Brand pencil, one eraser, and one pencil sharpener.

\subsection{Testing Process}

A one-to-one testing method was used. Subjects were required to first complete the LSRA and the UCLA loneliness scale and then perform the Mandala Painting test. This test consisted of the subjects randomly selecting one of the six Mandala templates and paint it freehand while writing down their thoughts while painting. The Mandala Characteristic Scale was completed by the tester according to the Mandala works and the subject's feeling while 
producing the painting as well as thinking associated with the painting after the subject had finished. The testing process lasted approximately 60 minutes. Painting analysis were performed by licensed psychoanalysts who had received Mandala paintings analysis training.

\subsection{Data Processing}

All collected data was entered into SPSS13.0 for descriptive statistics, t test, chi-square test, correlation analysis, and regression analysis.

\section{RESULTS}

\subsection{Self Stage and Naming Characteristics of the Elderly}

The self stage and nomination of Mandala works of the subjects appear in Tables 1 and 2. The studies showed that subject self-motivation gave priority to the following stages: integration (35\%), protection $(23.3 \%)$, and condensation stage $(15 \%)$ in the self-determination phase. The surmounting stage accounted for only $5 \%$. In the Mandala works naming phase, subjects identified the works with flowers $(30 \%)$, stars $(21.7 \%)$ and the sun $(13.3 \%)$.

Table 1. Distribution of Six Self-Motivation Stages (\%)

\begin{tabular}{lllllll}
\hline & Protection & Differentiation & Condensation & Integration & Guide & Surmounting \\
\hline Times & 42 & 15 & 27 & 63 & 24 & 9 \\
Proportion & 23.33 & 8.33 & 15.00 & 35.00 & 13.33 & 5.00 \\
\hline
\end{tabular}

Table 2. Main Image Distribution in Mandala Works Nomination (\%)

\begin{tabular}{lllllll}
\hline & Flower & Sun & Wheel & Star & Nature & Other \\
\hline Times & 54 & 24 & 12 & 39 & 15 & 36 \\
Proportion & 30.00 & 13.30 & 6.70 & 21.70 & 8.30 & 20.00 \\
\hline
\end{tabular}

\subsection{Gender Difference in Mandala Characteristics, Life Satisfaction, and Loneliness}

Gender differences in life satisfaction, Ioneliness, and Mandala characteristics are shown shown in Table 3 . The results indicate that elderly females have significantly higher scores in life satisfaction, integration, and the sense of the sacred; and significantly lower loneliness scores than males.

Table 3. Gender Differences in Life Satisfaction, Loneliness, and Mandala Characteristics $(n=180)$

\begin{tabular}{lllll}
\hline Sense Factor & Total Score & Female & Male & t \\
\hline Security & $7.13 \pm 1.62$ & $7.38 \pm 1.58$ & $6.65 \pm 1.57$ & 2.90 \\
Order & $31.38 \pm 5.31$ & $32.10 \pm 5.13$ & $29.95 \pm 5.33$ & 2.62 \\
Condensation & $30.77 \pm 4.63$ & $31.38 \pm 4.78$ & $29.55 \pm 3.99$ & 2.55 \\
Integration & $31.10 \pm 5.12$ & $32.23 \pm 5.36$ & $28.85 \pm 3.68$ & $4.39^{* *}$ \\
of the Sacred & $6.55 \pm 1.41$ & $6.83 \pm 1.23$ & $6.00 \pm 1.56$ & $3.87^{*}$ \\
Life Satisfaction & $13.01 \pm 3.59$ & $13.49 \pm 3.42$ & $11.93 \pm 3.74$ & $4.72^{* * *}$ \\
Loneliness & $37.48 \pm 8.54$ & $36.40 \pm 8.74$ & $39.95 \pm 7.51$ & $-4.70^{* * * *}$ \\
\hline
\end{tabular}

Note: $p^{\star}<0.05, p^{\star *}<0.01, p^{* * *}<0.001$, the same below. 


\subsection{Correlation between Mandala Painting Features, Life Satisfaction, and Loneliness and Regression Analysis}

The correlations between life satisfaction and loneliness and the five features of Mandala works was analyzed. The results show significantly positive correlation between life satisfaction and senses of order, condensation and integration in their Mandala works, and a significantly negative correlation between loneliness and senses of security, order, condensation, and integration (Table 4).

Table 4. Correlation between Mandala Features and Life Satisfaction and Loneliness

\begin{tabular}{llllll}
\hline Senses & Security & Order & Condensation & Integration & of the Sacred \\
\hline Life Satisfaction & 0.05 & $0.20^{* *}$ & $0.23^{* *}$ & $0.19^{* *}$ & 0.06 \\
Loneliness & $-0.26^{* *}$ & $-0.30^{* *}$ & $-0.35^{* *}$ & $-0.37^{* *}$ & -0.09 \\
\hline
\end{tabular}

A stepwise regression analysis was performed by taking life satisfaction and loneliness as the dependent variable and Mandala painting features as the independent variable to further study the influence of the self-motivation on life satisfaction and loneliness of the elderly, the analysis results appear in Table 5 and Table 6.

Table 5. Regression Analysis of Mandala Painting Features Compared to Life Satisfaction

\begin{tabular}{lcccccccc}
\hline $\begin{array}{l}\text { Independent } \\
\text { Variable }\end{array}$ & $\begin{array}{c}\text { Non-standard Standard } \\
\text { Coefficient B }\end{array}$ & $\begin{array}{c}\text { Standard } \\
\text { Error }\end{array}$ & Coefficient & $\mathbf{t}$ & $\mathbf{p}$ & $\begin{array}{c}\text { Correlation } \\
\text { Coefficient } \\
\text { R }\end{array}$ & $\begin{array}{c}\text { Determination } \\
\text { Coefficient R2 }\end{array}$ & Rdjusted \\
R2
\end{tabular}

Table 5 demonstrated that a peaceful mood during the Mandala painting process was a better predictor of the life satisfaction and it could explain $11 \%$ of the variance of life satisfaction. The regression equation is: life satisfaction $=0.375$ $\times$ peaceful mood in painting +5.10 .

Table 6. Regression Analysis of Mandala Painting Feature Compared to Loneliness

\begin{tabular}{lcccccccc}
\hline $\begin{array}{l}\text { Independent } \\
\text { Variable }\end{array}$ & $\begin{array}{c}\text { Nonstandard } \\
\text { Coefficient B }\end{array}$ & $\begin{array}{c}\text { Standard } \\
\text { Error }\end{array}$ & $\begin{array}{c}\text { Standard } \\
\text { Coefficient }\end{array}$ & $\mathbf{t}$ & $\boldsymbol{p}$ & $\begin{array}{c}\text { Correlation } \\
\text { Coefficient } \\
\text { R }\end{array}$ & $\begin{array}{l}\text { Determination Adjusted } \\
\text { Coefficient R2 }\end{array}$ & R2 \\
\hline Constant & 61.51 & 5.38 & & 11.18 & 0.000 & & \\
$\begin{array}{l}\text { Concentration } \\
\text { of attention }\end{array}$ & -7.44 & 1.42 & -0.60 & -5.24 & 0.000 & 0.52 & 0.28 & 0.26 \\
$\begin{array}{l}\text { Increased } \\
\text { peripheral } \\
\text { color }\end{array}$ & 2.92 & 1.01 & 0.33 & 2.88 & 0.005 & & & \\
\hline
\end{tabular}

Table 6 showed that concentration of attention and increased peripheral color during the painting process was a better predictor of loneliness and could explain $26 \%$ of the variance in loneliness. The regression equation is: Ioneliness $=0.60$ $\times$ concentration of attention in painting +0.33 increased peripheral color +61.51 . 


\section{DISCUSSION}

\subsection{Self Motivation Characteristics of the Elderly}

The results show that the self stage of the elderly gives priority to the following stages: integration (35 $\%$ ); protection (23.3\%); and, condensation (15\%). A higher proportion of self-motivation in the integration and protection stages suggests that a majority of the elderly focus their attention on coordinating conflicts and pursuing a sense of security. This result is identical to the findings of Min Li, et al. ${ }^{[14]}$ that somatization, anxiety, and interpersonal sensitivity of the elderly was significantly higher than those in the normal templates in China. It found, in interviews, that the elderly often deal with complex relationships at the integration stage, such as, relationships between mother-in-law and daughter-in-law, intergenerational education, voluntary admission a home or institution for the elderly, and the like. These intense contradictions and conflicts arise in the collision of of traditional culture and modern civilization. Interviews found that death anxieties at the protection stage were more significant. The elderly people are also less likely to be at the surmounting stage (5\%), which is possibly due to the the fact that self-transcedence requires greater mental effort. The elderly are more inclined to enjoy a peaceful old age than one involving struggle and conflict.

The elderly selected Mandala works containing flowers $(30 \%)$, stars $(21.7 \%)$, and the sun $(13.3 \%)$. Blooms represent plant fecundity and symbolizes the protection stage of the self ${ }^{[15]}$. This is consistent with the finding of the elderly are mainly with the protection stage. Both the elderly people and students usually select Mandala works containing stars and the sun ${ }^{[1]}$. Jung argued that the ego and self relationship could be expressed by the metaphor of the earth and the sun. The sun and stars are common Mantra images ${ }^{[16]}$.

\subsection{Gender Difference of Mandala Painting Characteristics, Life Satisfaction and Loneliness of the Elderly}

The studies showed a significantly higher life satisfaction in women and a significantly lower loneliness than in elderly men. Weiwei Guo, et al. also found that women had more social contacts than men, and women are more likely to express their feelings via various ways. Elderly women had better life satisfaction and less loneliness ${ }^{[3]}$.

Elderly women have higher life satisfaction and less loneliness than elderly men. Is this situation related to self-motivation? Gender differences in the characteristics of Mandala works was examined to investigate this issue.

The results showed that elderly women had a significantly higher sense of integration and sense of the sacred in the Mandala painting works. Further analysis found that elderly women had a significantly higher integration in the pictures of Mandala works, such as, harmony and integrity, image internal/ external connection, balance of cool/warm colors, and the fitness of image and color and other items, and included a higher transcendence [sense of the sacred] feature in religious images and other items. $(p<0.01)$ These items reflect that the elderly women are more prone self-motivated in terms of integration ${ }^{[14]}$. In daily life, they are better at coordinating relations and contradictions and get beyond predicaments via faith.

\subsection{Relationships between Mandala Painting Features and Life Satisfaction and Loneliness}

The related analyses showed a significantly positive correlation between life satisfaction and the senses of order, condensation, and integration reflected in Mandala works, and a significantly negative correlation between loneliness and the senses of order, condensation, and security in Mandala works $(p<0.05)$. This is consistent with the psychoanalysis hypothesis that the self affects the mental health.

The regression analysis is: life satisfaction $=$ $0.375 \times$ peaceful mood in painting +5.10 . A peaceful mood in painting can explain $11 \%$ of the variance in life satisfaction. This is due to the painter being in a peaceful mood is more comfortable in dealing with various relationships (cool/warm colors, trend/ divergence, differences between the psychological image and the actual picture) during the painting process. It reflects a higher painter self-motivation of integration ${ }^{[14]}$. Some studies show that a higher motivation of integration promotes an individual's self-harmony ${ }^{[15]}$. It can be understood that the normal performance of self-motivation of integration is the main cause for the elderly life satisfaction.

Concentration and increased peripheral color in the painting process are better predictors for the loneliness and may explain a $26 \%$ variance of loneliness. The regression equation is: Ioneliness 
$=0.60 \times$ concentration of attention in painting + 0.33 increased peripheral color +61.51 . Increased peripheral color is a habit showing weaker protective motivations and a lower sense of security which reflects a blocked self-motivation for protection ${ }^{[14]}$. The greater concentration brought by painting means the painter can concentrate on the events in their life and indicates that self-motivation is not blocked. A lack of self-motivation for protection and impaired concentration may be important factors in forming elderly loneliness.

In summary, the results of this study show that self-motivation has a significant influence on the mental health of the elderly, including life satisfaction and loneliness.

\section{REFRENCES}

1. Wang $\mathrm{XH}$, Zhou HF. Current situation and the relationship of subject well-being and life quality and loneliness of the elderly. Chin J Geront. 2010; 30(5): 676-677.

2. Wang FX, Xu FF, Li F. Current situation of subject well-being and loneliness of the elderly. Chin J Geront. 2011; 31(13): 533-535.

3. Guo WW, Wang YZ. Loneliness of urban aged people and its influencing factors. China J Health Psych. 2013; 21(9): 358-360.

4. Chen CR. Feature, function and application of mantra. Guangzhou: Doc Dissertation South China Norm Univ. 2012; 42-50.

5. Chen CR, Shen HY. The theory about self of Jung and post-Jungian. Psych Explor. 2011; 31(5): 391-396.

6. Chen $\mathrm{CR}, \mathrm{Gao} \mathrm{YH}$. Analysis of children' mandala painting: Theory and practice. Guangzhou: Jinan University Press. 2014; 156-161.

7. Jung CG. The collected works of C. G. Jung - Image analysis. Changchun: Changchun Publishing House. 2014; 67-81.

8. Chen CR, Gao YH. Road of mind: Self-healing picture book. Guangzhou: Jinan University Press. 2014; 2-4.

9. Kim SI, Bae J, Lee Y. A computer system to rate the color-related formal elements in art therapy

\section{FUNDING SUPPORT}

This work was supported by: a 2012 grant from the Education Science Planning Program of Guangdong titled "A Study on Relieving Students' Stress by Mandala Psychological Painting Technique" (program No.: 2012JK209); a 2013 grant from the Philosophy and Social Science Planning Program of Guangzhou titled "A Study on EEG Improvement of Anxiety and Depression by Mandala Painting-Taking Guangzhou College Students as an Example" (program No.: 13G70); and, a 2012 grant from the PhD Startup Fund of Guangzhou Medical University entitled "A Study on Promoting the Mental Health Mechanism of College Students by Mandala Painting Technique" (program No.: 2012C28).

assessments. Arts Psychother. 2007; 34: 223237.

10. Curry NA, Kasser T. Can coloring mandalas reduce anxiety? J Am Art Ther Assoc. 2005; 22: 81-85.

10. Chen CR, Zhou DW, Gao YH. Effect and mechanism of mandala drawing. Chin J Clin Psych. 2013; 21(1): 124-126.

11. Schrade C, Tronsky L, Kaiser DH. Physiological effects of mandala making in adults with intellectual disability. Arts Psychother. 2011; 38: 109-113.

12. Kim SI, Kang HS, Kim YH. A computer system for art therapy assessment of elements in structured mandala. Arts Psychother. 2009; 36(1): 19-28.

13. Li M, Guo JZ, Wang RM. Mental health of aging population in Shandong Province and its influencing factors. China J Health Psych. 2016; 24(5): 354-360.

14. Chen $\mathrm{CR}$, Gao YH. Mirror of the mind: mandala painting therapy. Guangzhou: Jinan University Press. 2014; 42-45.

15. Jung CG. Concerning mandala symbolism in CW9i. Princeton, NJ: Princeton University Press. 1950; 42-52. 